\title{
Habitat use of medium-sized carnivores in southeast Finland - key habitats for rabies spread?
}

\author{
Katja Holmala ${ }^{1} \&$ Kaarina Kauhala ${ }^{2}$
}

1) Finnish Game and Fisheries Research Institute, Helsinki Game and Fisheries Research, P.O. Box 2, Fl-00791 Helsinki, Finland (e-mail: katja.holmala@rktl.fi)

2) Finnish Game and Fisheries Research Institute, Turku Game and Fisheries Research, Itäinen Pitkäkatu 3 A, Fl-20520 Turku, Finland

Received 2 Jan. 2008, revised version received 22 Dec. 2008, accepted 6 Oct. 2008

Holmala, K. \& Kauhala, K. 2009: Habitat use of medium-sized carnivores in southeast Finland key habitats for rabies spread? - Ann. Zool. Fennici 46: 233-246.

Understanding the dynamics of a disease spread requires information on various aspects of the ecology of vector species. The habitat selection and habitat use of raccoon dogs (Nyctereutes procyonoides), badgers (Meles meles), red foxes (Vulpes vulpes) and domestic cats (Felis silvestris catus) were studied in southeastern Finland between 2000 and 2004. The aim was to find out the habitats where these species are most likely to come into contact and possibly transmit diseases, such as rabies, to each other. Raccoon dogs and badgers showed preference for fields and deciduous forests in all scales studied. Raccoon dogs favoured also watersides in summer and young mixed forests in autumn. Foxes and cats showed more individual variation in their habitat selection/use. Analysis of the overlapping areas of seasonal home ranges further demonstrated the significance of deciduous forests and fields. These, and also young mixed forests and open areas, could be called the risky habitats in terms of rabies spread.

\section{Introduction}

Many major epizootics of rabies have occurred in Europe over the past centuries with the domestic dog (Canis familiaris) and cat (Felis silvestris catus) as the main hosts and primary transmitters (vectors) of an infection to humans (Bunn 1991, Anderson et al. 1981). Since World War II, the red fox (Vulpes vulpes) has been the main vector of wildlife (sylvatic) rabies in central and western Europe (Wandeler et al. 1974, Chautan et al. 2000). The role of the raccoon dog (Nyctereutes procyonoides) has increased in northern and eastern parts of Europe in recent years (Holmala \& Kauhala 2006). The increase has been most prominent in the Baltic States. For instance in Lithuania, $52 \%(N=987)$ of the wildlife rabies cases in 2006 were in raccoon dogs (WHO 2006). Only recently the number of cases have decreased due to vaccination campaigns. During the epizootic of sylvatic rabies in Finland in the late $1980 \mathrm{~s}, 73 \%$ of the observed cases were in raccoon dogs and only $18 \%$ in foxes (Westerling 1991).

European badgers (Meles meles) and freeranging domestic cats are other potential vectors of rabies in northern Europe. Badgers are fairly susceptible to the rabies infection and they can transmit the virus easily (Wandeler et al. 1974, Smith 2002, Smith \& Wilkinson 2002). Signifi- 
cance of badgers as secondary vectors of rabies is probably greater than previously assumed. The free-ranging cats usually have an owner but are only seldom vaccinated against rabies. In 2006, 944 rabies cases were observed in cats in Europe, which was $10 \%$ of all observed cases and $32 \%$ of cases in domestic animals. Co-existence of two or more vectors increases the complexity of the epidemiology of rabies (Kaplan 1985, Blancou 1988).

In southern Finland, the raccoon dog, badger and red fox are common medium-sized carnivores. Semi-feral domestic cats range free in many agricultural areas and may well come into contact with wild carnivores during their nightly trips. They may thus be important vectors of some dangerous diseases and parasites, such as rabies, bovine tuberculosis (e.g. Vicente et al. 2007) or the parasite Echinococcus multilocularis, which pose a risk to humans.

The medium-sized carnivores also share resources. Species home ranges overlap largely (Kauhala \& Holmala 2006) and they have partly overlapping dietary requirements (Kauhala et al. 1998). The fox is the most carnivorous of the three wild species and raccoon dog the most omnivorous. Badgers use invertebrate prey more often than the two other species. There are even simultaneous observations of these species together with cats, visiting a bird feeder site. Raccoon dogs and badgers, and badgers and foxes, also occasionally use common dens (e.g. Kowalczyk et al. 2000 and authors' unpubl. data).

Because all these species share resources, it is likely that they also forage in the same habitats. This further increases the probability of contacts between them. Contacts (bites) between individuals determine the rate of rabies spread (White et al. 1995). Knowledge of the habitat use will aid us to understand the transmission events of diseases, such as rabies, and help to create models to predict the movements of epidemics and to plan preventive actions.

The aim of the present study was to examine the habitat selection within the study area and habitat use within the home ranges of the four carnivore species in different seasons. The main goal was to identify the so-called risky habitats where medium-sized carnivores are likely to contact and transmit diseases to each other, i.e. habitats they all favour and also use in the overlapping parts of their home ranges.

\section{Material and methods}

\section{Study area}

The study area (land area $110 \mathrm{~km}^{2}$ ) was located in the boreal zone, in Virolahti (southeastern Finland) about $9 \mathrm{~km}$ from the Russian border $\left(60^{\circ} 32^{\prime} \mathrm{N}, 2^{\circ} 41^{\prime} \mathrm{E}\right)$. The area was a mosaic of agricultural land and commercial forest: coniferous (spruce Picea abies, pine Pinus sylvestris), deciduous (silver birch Betula pendula, downy birch Betula pubescens, black alder Alnus glutinosa, grey alder Alnus incana, aspen Populus tremula, bird cherry Prunus padus, rowan Sorbus aucuparia) and mixed forests. Large ditches ran through the fields. Stone mines (granite) and large reed beds were also special features in the area. There was a small village in the middle of the study area. The mean temperature of the year was $5.1^{\circ} \mathrm{C}$, the mean being $-6.9^{\circ} \mathrm{C}$ in January and $17^{\circ} \mathrm{C}$ in July. Ground was covered with snow usually from November until April. Raccoon dogs, foxes and badgers were regularly hunted in the area.

\section{Radio tracking}

Space use was studied using radio-telemetry between autumn 2000 and summer 2004. We captured the animals using mainly wired or wooden baited traps (about 25 traps, distributed evenly in the study area). They were anaesthetized by an intra-muscular injection of ketamine hydrochloride. The animals were weighed, sexed and fitted with radio-collars (model TW-3, 138-138.5 $\mathrm{MHz}$, Biotrack, Dorset, UK) and plastic ear-tags (sheep tags, Dalton, UK). Only adults were fitted with radio-collars, except two juvenile foxes in autumn, when they had reached adult weight. Twenty-one raccoon dogs, eight badgers, six red foxes and 12 cats were included in the habitat analyses. The total number of fixes was $>8000$.

Radio tracking was done with a three-element Yagi-type antenna. Bearings were taken from at least two points, the time interval between the 
bearings being as short as possible (about five minutes) to minimize the error caused by animal movements. If the angle between the bearings was not close to $90^{\circ}$, we took a third bearing to make the location more accurate. Location error was tested earlier, and was found to be $<150 \mathrm{~m}$ in $77 \%$ of the cases (Kauhala \& Tilikainen 2002). We tried to locate the animals once every 15 minutes during the dark hours. The mean distance between the tracker and the animal was $563 \mathrm{~m}(290-910 \mathrm{~m})$ in a random sample of 30 locations (Kauhala et al. 2006). When possible, two animals with overlapping or adjacent home ranges were radio-tracked simultaneously. The mean length of tracking session was $5.0 \pm 1.19$ hours (Kauhala \& Holmala 2006)

\section{Home range calculations}

Individuals were the sample units (Kenward 1992). The number of locations needed was tested for each animal. The home-range size increases with the number of locations until it becomes asymptotic. This point indicates the minimum number of locations needed for reliable home-range size estimations (e.g. Odum \& Kuenzler 1955, Kauhala et al. 1993). Home ranges were calculated for individuals and seasons with enough data (Table 1).
We calculated home ranges with the software RANGES 6 (Kenward et al. 2003) using the fixed density Kernel method (Kernel 95\% or K95; Worton 1989) with the reference smoothing parameter (1.0). Species-specific core areas were defined from the utilization distribution curves: the core area is the point where the curve bends, i.e. the point of slope discontinuity (e.g. Jennrich \& Turner 1969, Kauhala et al. 1993). The species-specific core area was the median of individual core areas. We defined core areas of Kernel 60\% (K60) for raccoon dogs, 65\% (K65) for badgers, $60 \%$ (K60) for foxes and $80 \%$ (K80) for cats.

Total home ranges were calculated for the whole year to study the overall habitat selection within the landscape. The habitat compositions of the seasonal home ranges and core areas give a better picture of the habitat use within the home range. We defined two biological seasons: AprilJuly ("summer", breeding and pup rearing) and August-October ("autumn", dispersal and preparing for the winter). There were not enough data to test for differences between years.

We pooled the data for both sexes because there were no differences in home ranges sizes and habitat use (the proportions of each habitat in the home ranges and core areas) between sexes in any of the species (Kruskal-Wallis ANOVA: $P>0.05)$.

Table 1. The total home ranges (Kernel 95\%) and core area sizes (mean \pm SD [min-max]) for the raccoon dogs, European badgers, red foxes and domestic cats radio-tracked in summer and autumn in southeast Finland.

\begin{tabular}{|c|c|c|c|c|}
\hline & Size (ha) & $\begin{array}{c}\text { Number of home } \\
\text { ranges }\end{array}$ & Number of fixes & $\begin{array}{c}\text { Mean number of } \\
\text { fixes }\end{array}$ \\
\hline \multicolumn{5}{|l|}{ Raccoon dog } \\
\hline Total home range & $321 \pm 151$ [130-608] & 18 & $46-355$ & 165 \\
\hline K60 summer & $74 \pm 39[12-156]$ & 18 & $43-215$ & 85 \\
\hline K60 autumn & $73 \pm 52[3-225]$ & 19 & $31-166$ & 86 \\
\hline \multicolumn{5}{|l|}{ Badger } \\
\hline Total home range & $1090 \pm 681[498-2735]$ & 10 & $96-305$ & 187 \\
\hline K65 summer & $313 \pm 212[33-863]$ & 13 & $74-197$ & 123 \\
\hline K65 autumn & $161 \pm 141[33-277]$ & 10 & $31-142$ & 76 \\
\hline \multicolumn{5}{|l|}{ Fox } \\
\hline Total home range & $560 \pm 200[398-850]$ & 5 & $96-287$ & 214 \\
\hline K60 autumn & $105 \pm 78[23-227]$ & 6 & $47-108$ & 77 \\
\hline \multicolumn{5}{|l|}{ Cat } \\
\hline Total home range & $129 \pm 61[60-216]$ & 5 & $104-192$ & 135 \\
\hline K80 summer & $60 \pm 66[4-205]$ & 8 & $33-117$ & 79 \\
\hline K80 autumn & $61 \pm 45[3-139]$ & 11 & $27-135$ & 47 \\
\hline
\end{tabular}




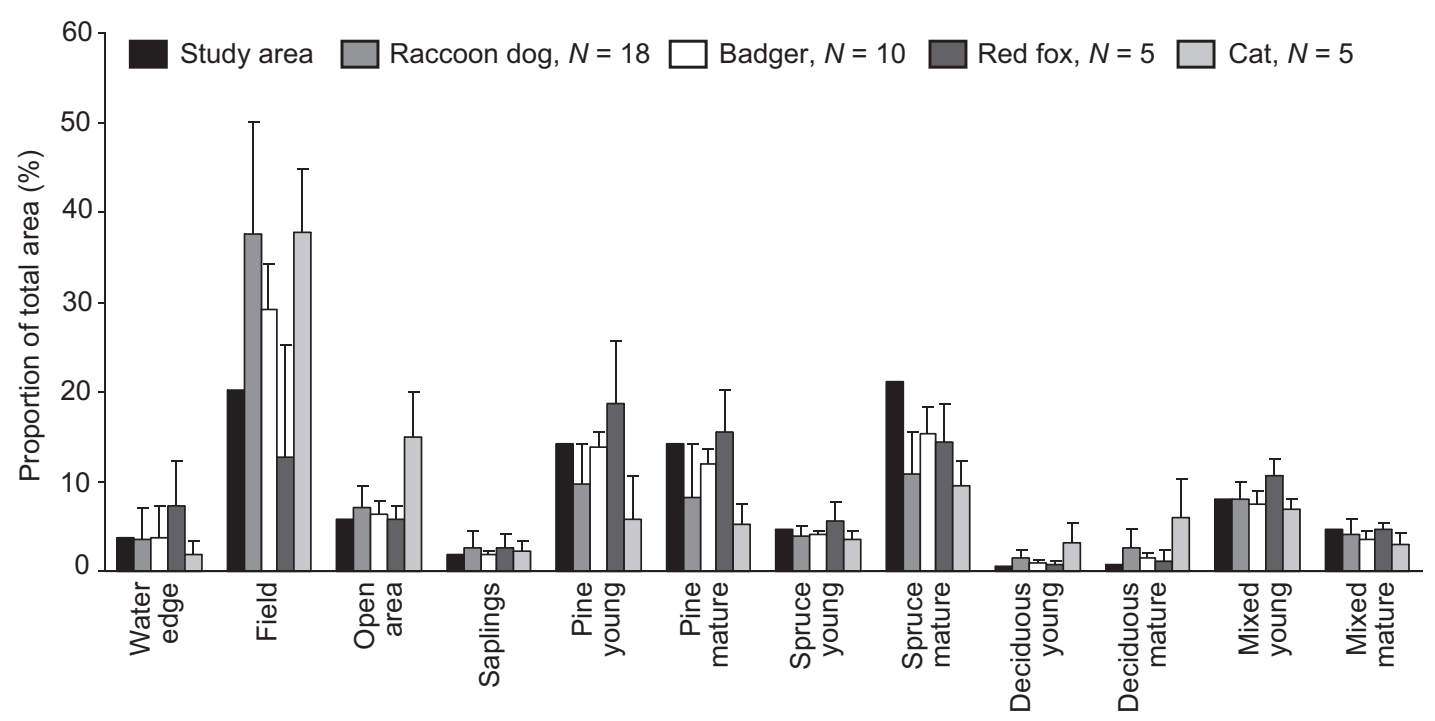

Fig. 1. The proportions (\%, mean + SD) of different habitats in the study area and in the total home ranges (Kernel $95 \%$ ) of raccoon dogs, European badgers, red foxes and domestic cats in SE Finland. Home ranges were calculated for the whole year.

\section{Habitat analysis}

A digital habitat map was obtained by combining digital maps of land and forest cover (National Land Survey of Finland), paper maps, self-digitised material and data from the field (habitat mapping). The resolution of the digital maps used was $50 \times 50$ meters. We checked the accuracy of the digital maps by comparing data collected from the field to the classification used in land and forest cover maps. Hand held GPS receiver was used for accurate locations in the field. We defined the study area as a rectangular area encompassing all radiolocations of the four species.

We divided the habitats into 12 classes: field (cereal fields and pastures), mature and young deciduous forest, mature and young pine forest, mature and young spruce forest, mature and young mixed forest, open area (including yards, roads, stone mines), waterside (including reed beds, sea shore, major rivers, ponds, large ditches) and sapling stand (including clear-cuts, and seed plantations $<10 \mathrm{yr}$ ). The forest types were divided into two age groups (young $<40$ years; mature $\geq 40$ years) according to their timber volume, following the classification used for southern Finland (Kurki et al. 1998). Timber volumes correlate strongly with the age of forest stand (Kurki et al. 1998). Age of the forest affects the field and shrub layers, which largely influence the food resources and shelter available for medium-sized carnivores.

The habitats available in the study area were mature spruce-dominated forest $(21 \%)$, fields (20\%), young pine-dominated forest (14\%), mature pine-dominated forest $(14 \%)$, young mixed forest (8\%), open areas (6\%), young spruce-dominated forest (5\%), mature mixed forest (5\%), watersides (4\%), sapling stands $(2 \%)$, young deciduous forest $(0.5 \%)$ and mature deciduous forest (1\%) (Fig. 1).

Habitat analyses were performed using Geographical Information Systems (ArcView 3.2, ArcGIS). Habitat selection was studied by comparing the habitat composition of the total home ranges to that of the study area. Habitat use within the home range can be described by comparing the habitat composition of the core area with that of the total home range (Porter \& Church 1987). Kauhala and Tiilikainen (2002) showed that if habitat patches are small and there is some location error, only $33 \%$ of the location fixes were in the correct habitat patch, whereas the habitat compositions of core areas were correct. We thus preferred to compare the 
habitat composition of core area with that of the total home range. Assuming that the habitat use differs from random, habitats can be ranked according to their relative use, and significant between-rank differences can be located (Aebischer et al. 1993).

We also analysed the habitat composition in the overlapping areas of the seasonal home ranges (K95) of different animals. Habitat composition of the overlapping areas was then compared with that of the whole study area. In theory, the common areas might be either ignored peripheral areas or contain preferred habitat patches due to valuable resources. By analysing the habitat composition of these areas we will get an accurate picture of the habitats where neighbouring individuals are most likely to contact and therefore where disease transmission is most likely to occur.

Cat home ranges are related to the location of their owners' houses and cat density in the study area was much higher than the number of individuals tracked. Thus, we decided not to analyse further the habitats in the overlapping areas. Moreover, cat home ranges were totally overlapped by the home ranges of other species. Also, the fox data were too scarce to permit compositional and overlap analyses. There were only one male fox and two vixens with overlapping home ranges. Only one fox was radio tracked in summer.

\section{Statistical analyses}

We used the method known as compositional analysis to overcome the problem of unit-sum constraint and non-independence of habitat proportions (Aebischer et al. 1993). When analysing the effects of landscape composition, the proportions of various habitats are not independent of each other, because various habitats share a fixed $100 \%$ of the landscape area (Kurki et al. 1998). To overcome this problem in compositional analysis, log ratios are used to examine proportional habitat use by individuals or groups of individuals. This MANOVA based technique is used to analyse the statistical significance of differences and the rank order of differences between two sets of data in which variables are represented as proportions. It enables ranking of preferred habitats. Unequal sampling of individual animals does not affect the overall analysis, provided that sampling intensity is adequate for deriving accurate estimates of mean habitat use or that at least the estimates from different animals are equally accurate or stable (Smith \& Racey 2005). For habitats with no proportional values, zeros were replaced with a value an order of magnitude smaller than the smallest proportion observed (Aebischer et al. 1993). Since the data were not normally distributed, we used randomised $P$ values. We did compositional analyses by using a Compositional Analysis 6.2 Add-In for the Microsoft Excel spreadsheet program (Smith 2006).

Preference indices were calculated for the foxes and cats when data were too scarce for the compositional analysis. The indices were calculated for each habitat to estimate habitat selection (K95/study area) and habitat use (species core/K95). Indices were calculated using the formula: $\ln$ (proportion used/proportion available) (Kenward 2001). Because not all variables were normally distributed (Kolmogorov-Smirnov one sample test), we used Wilcoxon signed-rank test to examine if habitat preferences differed from random use. Wilcoxon signed-rank test compares a median with a hypothetical value, which in our case was 0 , i.e. habitat use would equal the habitat availability. Compositional analysis and preference index method gave similar results when habitat use of domestic cats was studied (Kauhala \& Holmala 2008).

We used a Mann-Whitney $U$-test to examine differences between seasons in the home range size, use and overlap. Differences were considered significant at $P<0.05$.

\section{Results}

\section{Habitat selection and habitat use within species}

The most common habitat in the total home ranges and seasonal core areas of raccoon dogs was field (Figs. 1, 2A and B). In core areas the proportions of field $(U=4.0, P<0.001)$, open areas $(U=75.0, P=0.004)$ and sapling stands 

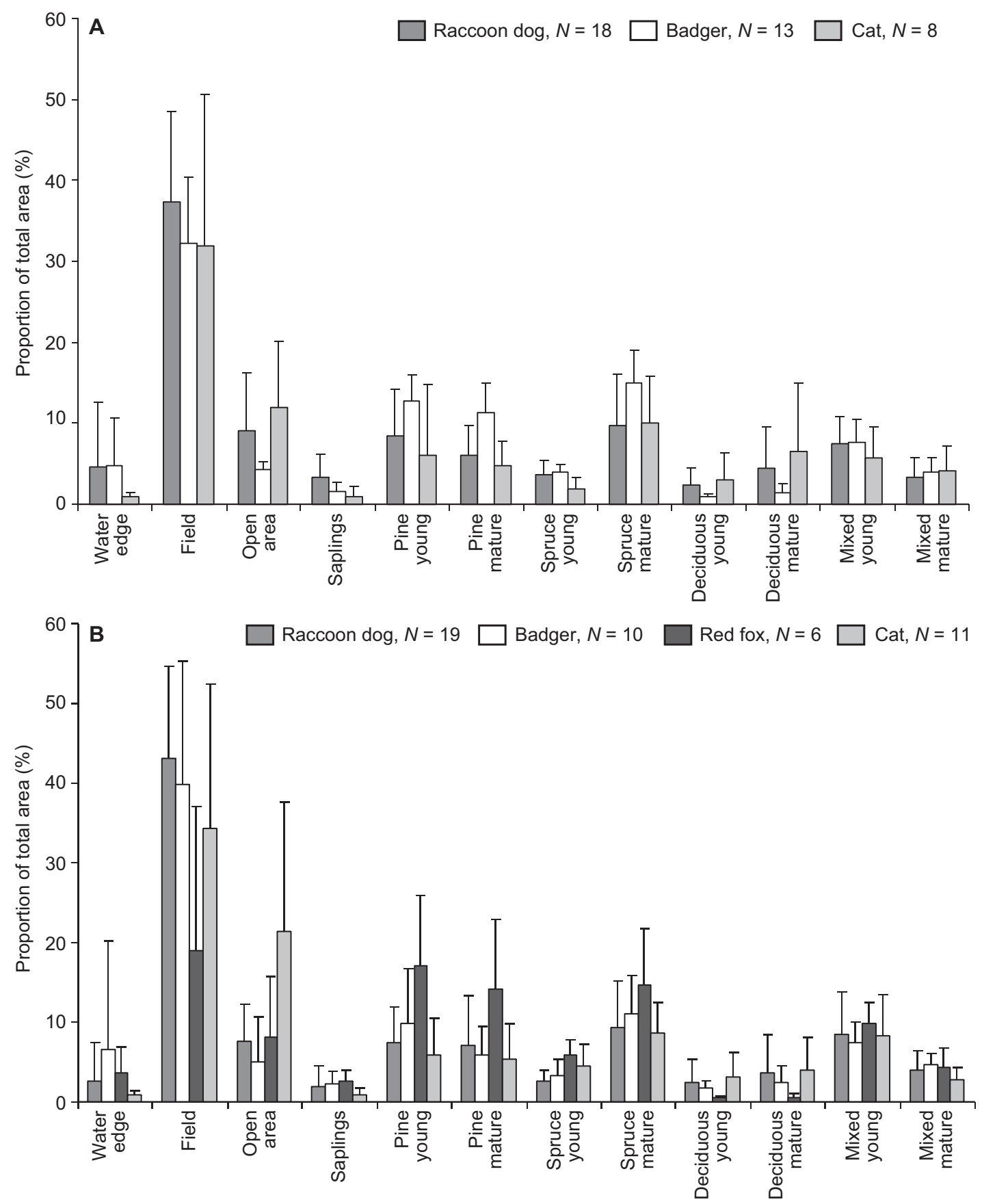

Fig. 2. The proportions (\%, mean + SD) of different habitats in the seasonal core areas of raccoon dogs, European badgers, red foxes and domestic cats in SE Finland. (A) Summer (no data for red fox), and (B) autumn core areas. Core areas for different species: raccoon dog Kernel $60 \%$, badger $65 \%$, fox $60 \%$ and cat $80 \%$.

$(U=308.000, P<0.001)$ were higher in autumn than in summer and those of young $(U=328.0$, $P<0.001)$ and mature spruce forests $(U=33.0$,
$P<0.001)$ higher in summer.

Raccoon dogs selected deciduous forests and fields from the landscape. The least selected 
habitat was mature coniferous forest (Table 2). The seasonal habitat use by the raccoon dogs was not random either. The most used habitats within home ranges in summer included young deciduous forest, fields and watersides, whereas in autumn fields, mature deciduous forest and young mixed forest were preferred.

The habitat proportions in the overlapping areas of seasonal total home ranges, i.e. common areas were compared with those available in the landscape to include a temporal aspect of overlap. The most common habitats in the overlapping parts of raccoon dog home ranges were fields, but also open areas (in both seasons) and young pine forest (in summer) were frequently included (Fig. 3). The most selected habitats were deciduous forests and fields in both seasons (Table 3). Also open areas were included among the most preferred habitats in autumn.

Total home ranges of badgers were the largest of all four species studied (Table 1). The most common habitat in the total home ranges and in seasonal core areas was field (Figs. 1, 2A and $\mathrm{B})$. The core areas included higher proportions of mature pine forest $(U=20.0, P=0.005)$ and mature spruce forest $(U=32.0, P=0.041)$ in summer than in autumn and higher proportion of young deciduous forests $(U=105.0, P=0.013)$ in autumn $\left(N_{\text {summer }}=13, N_{\text {autumn }}=10\right)$. The core area was also larger in summer than in autumn ( $U=31.0, P=0.035)$. Badgers tended to select both deciduous forests and fields over other habitats in the study area (Table 2). The seasonal habitat use of badgers differed significantly from random use in autumn but no statistical significance was found in summer (Table 2). The three most used habitats in autumn were young deciduous forest, fields and mature deciduous forest. In the overlapping parts of badger home ranges the most common habitats in summer and in autumn were the same: fields, mature spruce forest and young pine forest (Fig. 3). However, badgers selected especially deciduous forests and fields in summer (Table 3).

Total home ranges and autumn core areas of foxes were larger than those of raccoon dogs or cats (Table 1). The four most common habitats in total home range and in autumn core were young and mature pine forests, mature spruce forest and field (Figs. 1 and 2B). There was so
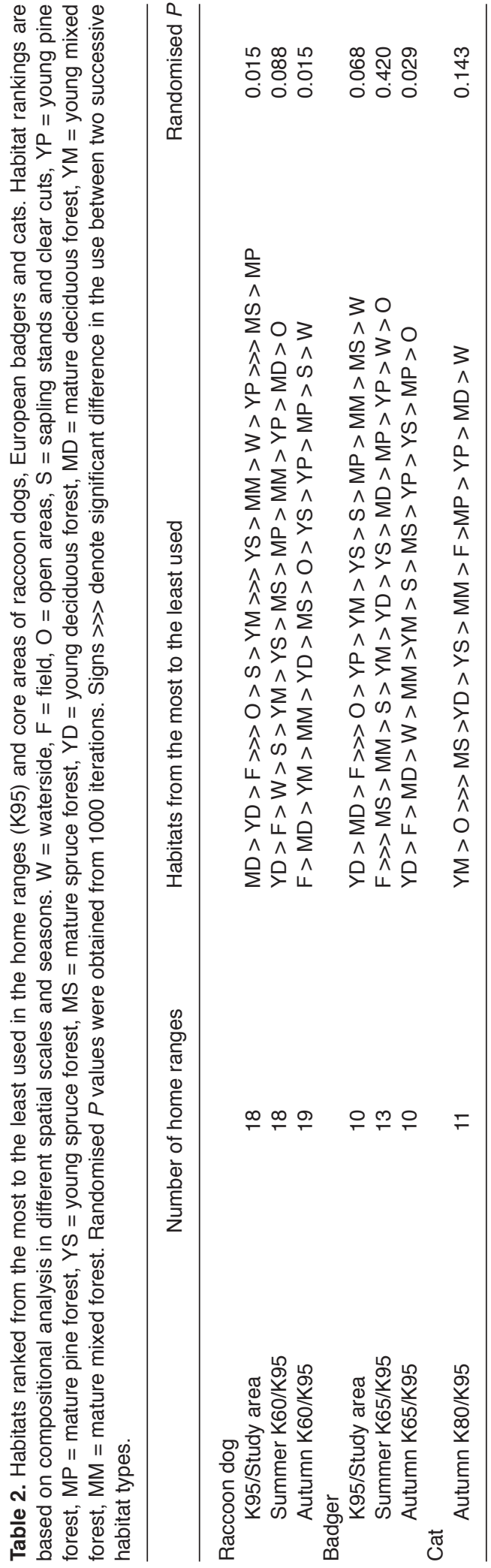


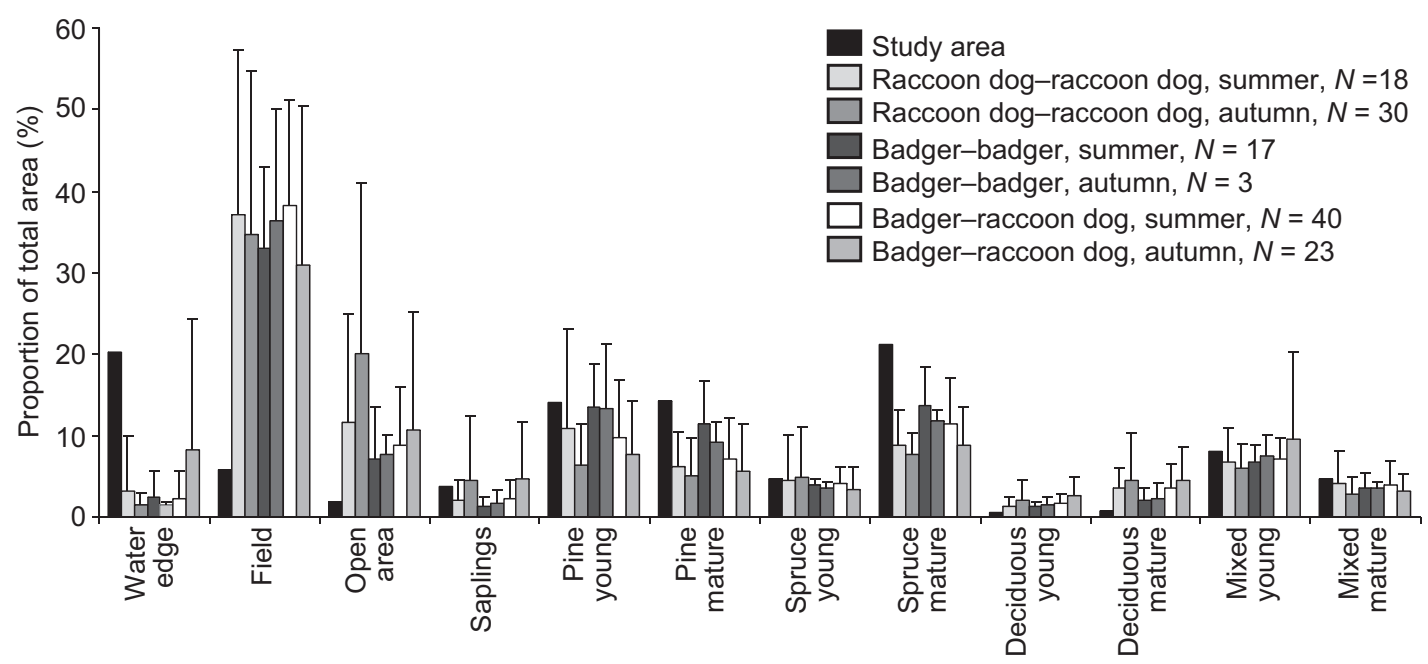

Fig. 3. The proportions (\%, mean + SD) of different habitats in the overlapping areas of seasonal home ranges of raccoon dogs and European badgers in SE Finland.
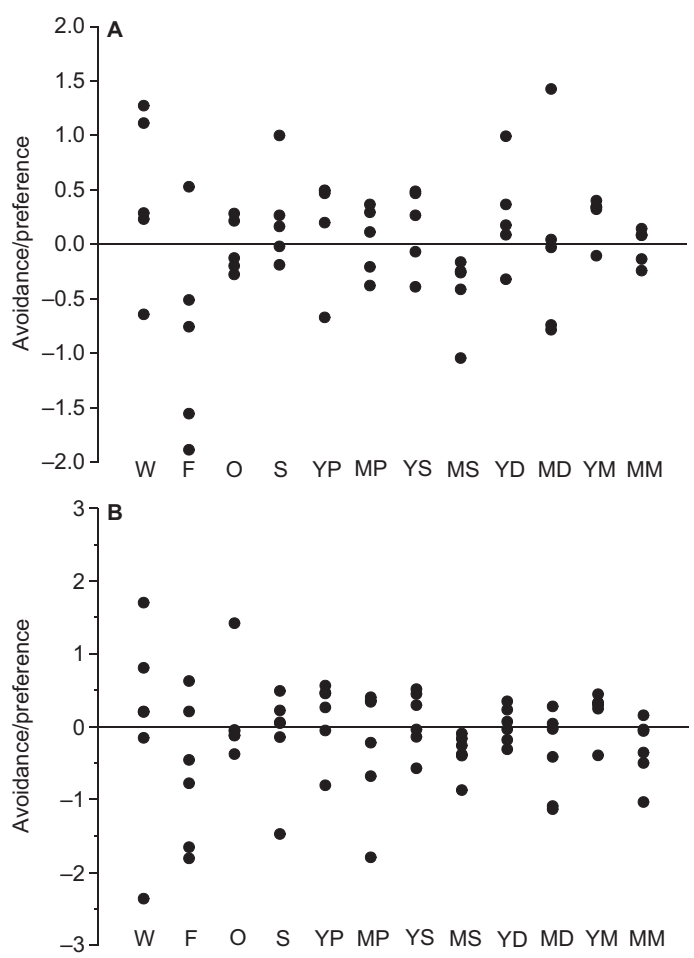

Fig. 4. Habitat selection and use by foxes according to preference indices. (A) Habitat selection within the landscape, $N=5$, (B) Habitat use within the home in the autumn, $N=6 . \mathrm{W}=$ waterside, $\mathrm{F}=$ field, $\mathrm{O}=$ open areas, $\mathrm{S}=$ sapling stands, $\mathrm{YP}=$ young pine forest, MP = mature pine forest, $\mathrm{YS}=$ young spruce forest, $\mathrm{MS}=$ mature spruce forest, YD = young deciduous forest, $\mathrm{MD}=$ mature deciduous forest, $\mathrm{YM}=$ young mixed forest, $\mathrm{MM}=$ mature mixed forest. much individual variation in the habitat selection of foxes within landscape level that only the preference indices for mature spruce forest differed from random use (less selected) (Wilcoxon signed-rank test: $P=0.042, N=5$; Fig. 4A). On the other hand, four foxes out of five seemed to select watersides, young pine forests, young deciduous forests and young mixed forests from the landscape and only one seemed to select fields. In autumn core areas, foxes used almost all habitats according to individual preferences (Fig 4B). However, mature spruce forest was not preferred by any of the foxes.

The total home ranges of cats were the smallest of the four species studied (Table 1). Field was the most common habitat in the total home range (Fig. 1). In the core areas of cats field and open area were the most common habitats during both seasons (Fig. 2A and B). There were less young spruce forests in the core area in summer than in autumn $(U=72.5, P=0.019)$. According to preference indices, cats selected deciduous forests (Wilcoxon signed-rank test: $P=0.043$, $N=5$ ), open areas and fields from the landscape more often than expected ( $P=0.042$; Fig. 5A). None of the cats selected mature coniferous forests $(P=0.042)$ and mature mixed forest $(P=$ $0.043)$. One individual had opposite preferences than other cats for almost all habitats. Cats used watersides within their home ranges in summer least of all habitats (Wilcoxon signed-rank test: 

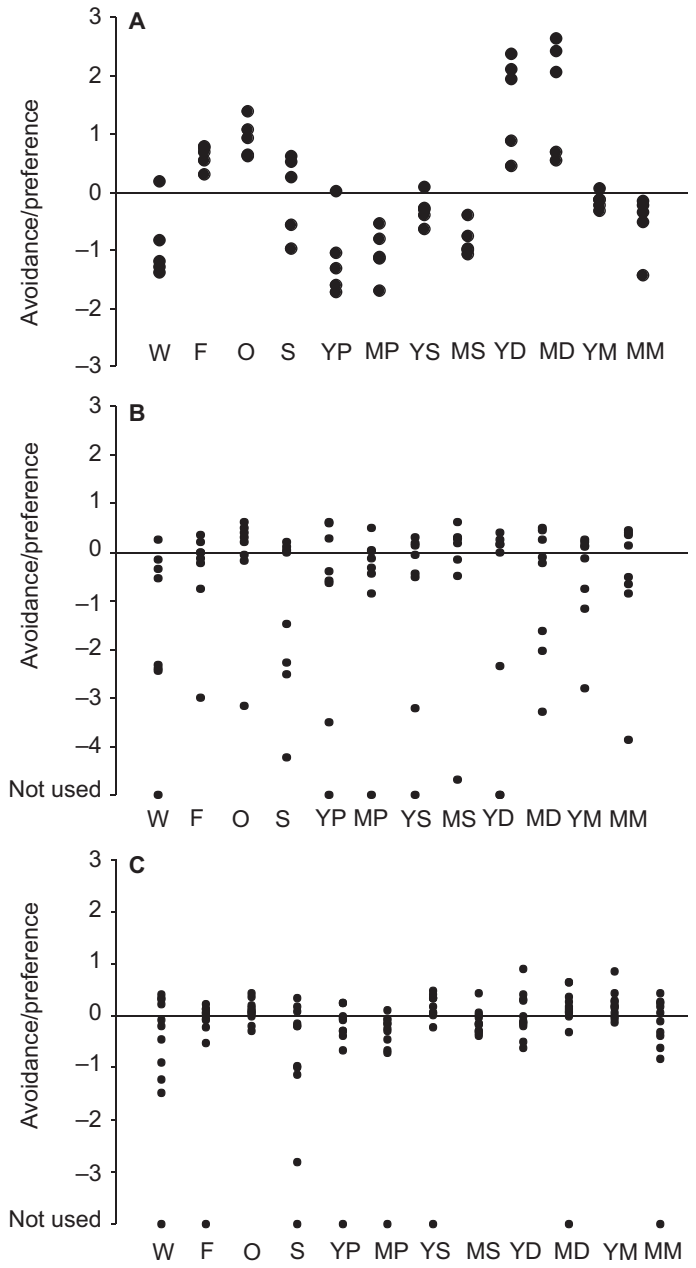

Fig. 5. Habitat selection and use by cats according to preference indices. (A) Habitat selection within the landscape, $N=5$. (B) Habitat use within the home range in summer, $N=8$. (C) Habitat use within the home range in autumn, $N=11$. $\mathrm{W}=$ waterside, $\mathrm{F}=$ field, $\mathrm{O}=$ open areas, $\mathrm{S}=$ sapling stands, $\mathrm{YP}=$ young pine forest, $M P=$ mature pine forest, $Y S=$ young spruce forest, $\mathrm{MS}=$ mature spruce forest, $\mathrm{YD}=$ young deciduous forest, $\mathrm{MD}=$ mature deciduous forest, $\mathrm{YM}=$ young mixed forest, $\mathrm{MM}=$ mature mixed forest.

$P=0.034, N=8$; Fig. 5B). The preference indices for the use of other habitats did not differ from zero $(P>0.05)$. In autumn the most used habitats were young spruce forest $(P=0.029$, $N=11)$, mature deciduous forest $(P=0.043)$ and young mixed forest $(P=0.021)$ (Fig. 5C). Mature pine forest was used less than expected $(P=0.009)$.

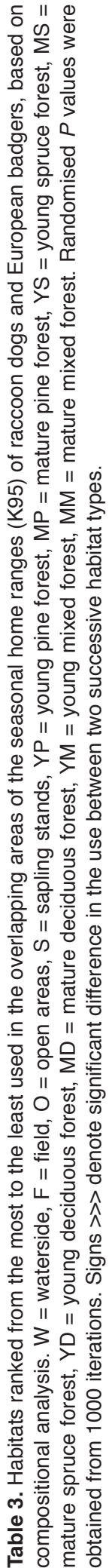

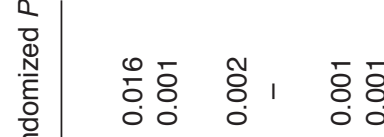

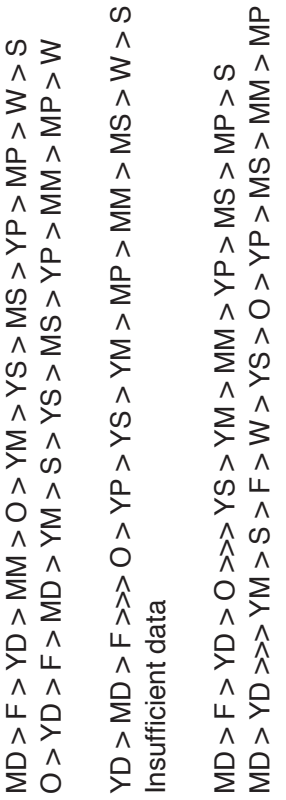

$\stackrel{\infty}{\infty} \sim^{\infty}$ 유

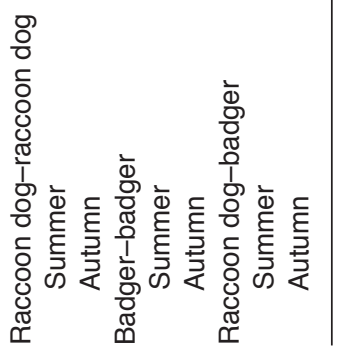




\section{Habitats in the areas shared by different species}

The most common habitats in the overlapping areas of badger and raccoon dog home ranges in summer were fields, mature spruce forest and young pine forest, whereas in autumn most common habitats were fields and open areas (Fig. 3). The habitat proportions in the overlapping areas in both seasons were significantly different from those available in the landscape (Table 3). In summer, the most often selected habitats were fields and deciduous forests. Also in autumn, the animals selected deciduous forests significantly more often than the other habitats.

The overlap between the home ranges of cats and badgers, and between raccoon dogs and cats was high, since most of the cat home ranges were within the home ranges of badgers and raccoon dogs. In fact, one badger home range held within several cat home ranges. Consequently, the habitat composition of the overlapping areas was equal to that of cat home ranges. Because only in one case home ranges of fox and raccoon dog overlapped, no results are presented for foxes.

\section{Discussion}

\section{Habitat selection and use of individual species}

In the study, raccoon dogs selected deciduous forests and fields and had smaller home ranges than badgers (Table 2). In their original range, raccoon dogs inhabit areas of forested streams or river valleys, and areas surrounding lakes, where thick undergrowth, marshes or reed beds provide dense cover (Ward \& Wurster-Hill 1990). Raccoon dogs favoured young deciduous forests, fields and watersides within their home ranges in summer in southeast Finland. Also in south-central Finland, shore areas were favoured in early summer and also to some extend in autumn (Kauhala 1996). Moreover, in Russia and Ukraine, raccoon dogs were frequently found near water or in damp meadows, swamps and alluvial soils (Nasimovich \&
Isakov 1985, Woloch \& Rozenko 2007). In contrast to our study, in northeast Germany raccoon dogs did not show preference for most habitat types (Drygala et al. 2008). Furthermore, water surface and settlements were avoided all year round. However, watersides with dense undergrowth provide abundant food (e.g. frogs) and shelter for raccoon dogs during early summer.

In autumn, raccoon dogs favoured fields, mature deciduous forest and young mixed forest in the study area (Table 2). There may be plenty of food (e.g. wild berries, cereals, insects, small mammals) available in these habitats. In addition, ditches going through fields and small forests patches provide e.g. cover and food for both raccoon dogs and badgers and might affect the high utilisation of fields. In south-central Finland, spruce and mixed forests were favoured in autumn due to abundant wild berries in these forests (Kauhala 1996). In Ukraine deciduous forests and gardens were frequently, but fields and coniferous forests less frequently used by raccoon dogs in autumn (Woloch \& Rozenko 2007). Also our results showed that coniferous forests are not ideal environment for raccoon dogs. The overlapping parts of the home ranges of raccoon dogs included the same favoured habitats; in summer deciduous forests and field, and in autumn also open areas (Table 3). Thus, encounters between neighbouring raccoon dogs may happen in patches of these habitats.

As in our study area, badgers selected patches of agricultural land in Sweden (Seiler et al. 1995). Hence, permanent pastures and deciduous forests are important for badgers as these habitats may house large populations of earthworms (Brøseth et al. 1997). This is emphasised further by badger diet in southern Finland; around one fourth of diet consists of invertebrates (Kauhala et al. 1998). However, earthworms are scarce in coniferous and mixed forests (e.g. Brøseth et al. 1997). In these habitats (like in Finland) badgers have to search also for other food items and move over large areas. In Denmark, badgers did not have common habitat preferences, which suggests that they exploited food resources occurring in all different habitats (Elmeros et al. 2005 ) or that the methods used did not reveal the habitat selection in this kind of landscape.

In the present study, fields were among the 
most used habitats by badgers both in summer and autumn (Table 2). In northeast England grassland was the preferred habitat during autumn and summer (Palphramand et al. 2007) and it was the key habitat determining badgers ranging behaviour. Furthermore, in Wytham Woods in England, badger home ranges decreased as the area of pasture increased (Kruuk \& Parish 1982, da Silva et al. 1993). However, changes in food availability and population density elsewhere have not led to changes in territory size (Roper et al. 1986, Cheeseman et al. 1987). Even though the compositional analysis of habitat use did not give significant results for summer in our study area, it is unlikely that the habitat use of badgers is random. Indeed, fields were used significantly more than any other habitat in summer. It could be that, as in Sweden, badgers showed weaker biotope preference in summer and foraged in several biotopes (Seiler 1992). Furthermore, badgers used deciduous forests more than expected in autumn. Even though the home ranges were smaller, they contained similar proportions of deciduous forests and fields as in summer. Thus, these habitats played important role in both seasons in southeastern Finland. This is emphasised even further by the fact that the common areas of overlapping home ranges of badgers contained these habitats more than they were available in the landscape in general.

Foxes did not favour fields in our study area, although in Finland the fragmentation of forest area by agricultural land has been shown to increase fox abundance, peaking at 20\%-30\% of agricultural land (Kurki et al. 1998). Interestingly, the foxes in our study area lived in two distinct areas, one dominated by forests and one close to human settlement and several fields. Probably the adaptation of foxes to the intensively used farmland in Finland is still in process as it is in Poland (Goldyn et al. 2003). Alternatively, the classification of habitats could be too coarse or too fine to reveal the real habitat selection of foxes or they might select a combination of habitats instead of one habitat. No clear conclusions of the habitat selection of foxes can be drawn due to large individual variation and a small data set.

Foxes used almost all habitats according to individual preferences (Fig. 4B). Only mature spruce forest, the most abundant habitat available, received similar responses from all foxes - it was used less than expected. But for foxes as a species, no clear conclusions regarding habitat preferences within the home range in autumn could be drawn due to insufficient data. In heterogeneous areas, where a number of resources are available at the same time in different habitats, foxes selected a diversity of habitats rather than any one in particular (Cavallini \& Lovari 1994, Lovari et al. 1996, Lucherini \& Lovari 1996). This might be true also in our study area. Moreover, foxes might even choose some other elements like field-forest edges over other habitat types. In general, prey availability seems to be the most important factor affecting habitat use of foxes (Jones \& Theberge 1982, Halpin \& Bissonette 1988).

Cat home ranges were largely pre-determined by the location of their owners' houses. Therefore cats seemed to select habitats, which were usually close to the houses in our study area, such as the small patches of deciduous forests, open areas and fields. These are also the habitats where cats are most likely to come into contact with raccoon dogs or badgers. In Scotland, feral domestic cats selected stream edges and woodland habitat types and avoided pasture and heather moorland (Daniels et al. 2001). Our cats were mainly farm and semi-feral cats and humans provided the majority of food for them. Hence, at least one basis for habitat selection (food resources) in our study area may differ from that of Scotland.

There was a lot of individual variation in the habitat preferences of cats in both summer and autumn (Fig. 5B and C). Open area was important habitat for cats in general. Moreover, farm cats have been observed to spend majority of their time within the farm area (Barrat 1997). Also in Hungary, home ranges of domestic cats were characterised by proximity to human settlements (Biró et al. 2004). Thus, the habitats surrounding the farms influence the habitats available for each cat. In Italy, cats used mainly habitats providing cover but avoided cultivated fields (Genovesi et al. 1995). In addition in USA, cats often used corridors between habitat patches but fields less often than expected by chance (Gehring \& Swihart 2003). 


\section{Contact zones between species}

Similarities of the habitat preferences and use enable us to determine risky habitats for contacts i.e. the contact zones for raccoon dogs, badgers and cats. These species selected deciduous forests and fields from the landscape more often than expected. These habitats were also among the most used habitats within raccoon dog and badger home ranges. Moreover, analysis of the habitats in the temporally overlapping parts of home ranges demonstrated again the significance of deciduous forests and fields for raccoon dogs and badgers in both summer and autumn. Thus, the contact zones could easily be identified as deciduous forests and fields. Taking into account the habitat use of cats also young mixed forests and open areas could be called risky habitats. Results also support the interpretation that the common areas contain habitat patches that are preferred due to some valuable resources.

Badgers, foxes and especially raccoon dogs occasionally visit yards and back gardens of houses making also these areas possible contact zones. In yards, these species are likely to come into contact especially with free-ranging domestic cats. Because of the dense cat population, the contact rate between individual cats, and between cats and other species, is probably high (Kauhala et al. 2006). Our results show that cats use the same risky habitats as wild mediumsized carnivores.

\section{Habitats and the spread of rabies}

Frequency of encounters between foxes and contact rate of rabies vary between habitats (Macdonald \& Bacon 1982). Other studies have indicated that habitat types have influenced the spread (speed and intensity) of rabies (e.g. Steck \& Wandeler 1980, Pool \& Hacker 1982, Carey \& McLean 1983, Sanson \& Pearson 1997 in Gylys et al. 1998). It is also known that the spatial spread of rabies occurs either within territory, through neighbour-to-neighbour infection or inter-territorial movements (temporary and permanent dispersal) of infected animals. In high fox density, the non-dispersing animals probably determine the rate of rabies spread (Saunders et al. 1997). Thus, habitat use, home range utilization and overlap play important roles in understanding the risk of rabies transmission and rabies dynamics.

Kauhala and Holmala (2006) calculated earlier that there was a high level of overlap between home ranges both within and between species, the greatest overlap being between members of raccoon dog pairs (84\%) and between raccoon dogs and badgers $(30 \%-73 \%)$. All species used the shared areas fairly often; $16 \%-79 \%$ of the locations were in the overlapping areas of the home ranges. Kauhala and Holmala (2006) further demonstrated that interspecies contacts (temporal overlap between individuals), were frequent, especially those between badger-badger and raccoon dog-badger pairs. The estimated contact rate (number of possible contacts during 3-night period) was so high (2.6-7.9) that a diseased individual would infect some individuals of the other species. Results of the present study also demonstrate that the contacts between badgers and raccoon dogs could be even more likely than previously assumed, because both species favour the same habitats in the common areas.

In Finland, rabies vaccines are distributed twice a year: in autumn and in spring. It is known that for example for foxes, the maximum vaccination bait uptake by resident individuals would be achieved by placing the highest density of baits in the preferred habitats (Saunders et al. 1997). During the dispersal time of raccoon dogs in autumn the most used habitats included field, deciduous forests and mixed forests. Also the shared parts of overlapping home ranges included deciduous forests more than expected in autumn. Moreover, densities of raccoon dogs, foxes and badgers are highest in autumn. In the study area the raccoon dog density in autumn was estimated to be 21 individuals $/ 10 \mathrm{~km}^{2}$, fox density $6.5-8.1$ foxes $/ 10 \mathrm{~km}^{2}$ and a minimum density of 2.6 badgers $/ 10 \mathrm{~km}^{2}$ (Kauhala et al. 2006). Thus, if possible, vaccine baits should be distributed mainly in these most used habitats taking into account the total densities of the target species.

In case of an epidemic or to prevent the outbreak of rabies, targeting the control measures to the most used habitats, deciduous forests and fields, could result in a more cost-effective and 
rapid eradication of the disease. For badgers and raccoon dogs these are the same habitats. Probably targeting the actions to these habitats would work well also for cats. In Finland, the rabies vaccination of pet cats is not regulated. However, the vaccinations of cats, especially in rural areas, should therefore be strongly recommended. We need still more research to be able to really define the risky habitats for foxes.

\section{Acknowledgements}

We wish to thank S. Sirkiä and two anonymous referees for their comments on the manuscript. We are grateful to the field workers, local hunters, and especially T. Rainio and S. Rintelä for their assistance. The Ministry of Forestry and Agriculture, Finnish Cultural Foundation and the Science Foundation of Helsinki University offered financial support.

\section{References}

Aebischer, N. L., Robertson, P. A. \& Kenward, R. E. 1993: Compositional analysis of habitat use from animal radiotracking data. - Ecology 74: 1313-1325.

Anderson, R. M., Jackson, H. C., May, R. M. \& Smith, A. M. 1981: Population dynamics of fox rabies in Europe. Nature 289: 765-771.

Artois, M. \& Aubert, M. F. A. 1985: Behaviour of rabid foxes. - Revue d'Écologie 40: 171-176.

Brøseth, H., Knutsen, B. \& Bevanger, K. 1997: Spatial organization and habitat utilization of badgers Meles meles: effects of food dispersion in the boreal forest of central Norway. - Mamm. Biol. 62: 12-22.

Barratt, D. G. 1997: Home range size, habitat utilization and movement patterns of suburban and farm cats Felis catus. - Ecography 20: 271-280.

Biró, Z., Szemethy, L. \& Heltai, M. 2004: Home range sizes of wildcats (Felis silvestris) and feral domestic cats (Felis silvestris f. catus) in a hilly region of Hungary. Mamm. Biol. 69: 302-310.

Blancou, J. 1988: Epizootiology of rabies: Eurasia and Africa. - In: Campbell, J. B. \& Charlton, K. M. (eds.), Rabies: 243-265. Kluwer Academic Publishers, Boston.

Bunn, T. O. 1991: Cat rabies. - In: Baer, G. M. (ed.), The natural history of rabies: 379-387. CRC Press, Boston.

Carey, A. B. \& McLean, R. G. 1983: The ecology of rabies: evidence of co-adaptation. - J. Anim. Ecol. 20: 777-800.

Cavallini, P. \& Lovari, S. 1994: Home range, habitat selection and activity of the red fox in a Mediterranean coastal ecotone. - Acta Theriol. 39: 279-287.

Chautan, M., Pontier, D. \& Artois, M. 2000: Role of rabies in recent demographic changes in red fox (Vulpes vulpes) populations in Europe. - Mammalia 64: 391-410.

Cheeseman, C. L., Wilesmith, J. M., Ryan, J. \& Mallinson, P.
J. 1987: Badger population dynamics in a high-density area. - Symp. Zool. Soc. London 58: 279-294.

Daniels, M. J., Beaumont, M. A., Johnson, P. J., Balharry, D., Macdonald, D. W. \& Barratt, E. 2001: Ecology and genetics of wild-living cats in the north-east of Scotland and the implications for the conservation of the wildcat. - J.Appl. Ecol. 38: 146-161.

da Silva, J., Woodroffe, R. \& Macdonald, D. W. 1993: Habitat, food availability and group territoriality in the European badger, Meles meles. - Oecologia 95: 558-564.

Drygala, F., Stier, N., Zoller, H., Boegelsack, K., Mix, H. M. \& Roth, M 2008: Habitat use of the raccoon dog (Nyctereutes procyonoides) in north-eastern Germany. - Mamm. Biol. 73: 371-378.

Elmeros, M., Madsen, A. B. \& Prang, A. 2005: Home range of the badger (Meles meles) in a heterogeneous landscape in Denmark. - Lutra 48: 35-44.

Gehring, T. M. \& Swihart, R. K. 2002: Body size, niche breadth, and ecologically scaled responses to habitat fragmentation: mammalian predators in an agricultural landscape. - Biological Conservation 109: 283-295.

Genovesi, P., Besa, M. \& Toso, S. 1995: Ecology of a feral cat Felis catus population in an agricultural area of northern Italy. - Wildlife Biology 1: 233-237.

Goldyn, B., Hromada, M., Surmacki, A. \& Tryjanowski, P. 2003: Habitat use and diet of the red fox Vulpes vulpes in an agricultural landscape in Poland. - Z. Jagdwiss. 49: 191-200.

Gylys, L., Chomel, B. B. \& Gardner, I. A. 1998: Epidemiological surveillance of rabies in Lithuania from 1986 to 1996. - Revue Scientifique et Technique/Office Internationales des Épizooties 17: 691-698.

Halpin, M. A. \& Bissonette, J. A. 1988: Influence of snow depth on prey availability and habitat use by red fox. Can. J. Zool. 66: 587-592.

Holmala, K. \& Kauhala, K. 2006: Ecology of wildlife rabies in Europe. - Mammal Rev. 36: 17-36.

Jennrich, R. I. \& Turner, F. B. 1969: Measurement of noncircular home range. - Journal of Theoretical Biology 22: 227-237.

Jones, D. M. \& Theberge, J. B. 1982: Summer home range and habitat utilization of the red fox (Vulpes vulpes) in a tundra habitat, northwest British Columbia. - Can. J. Zool. 6: 1800-1805.

Kaplan, C. 1985: Rabies: a worldwide disease. - In: Bacon, P. J. (ed.), Population dynamics of rabies in wildlife: 1-21. Academic Press, London.

Kauhala, K. 1996: Habitat use of raccoon dogs, Nyctereutes procyonoides, in southern Finland. - Mamm. Biol. 61: 269-275.

Kauhala, K., Helle, E. \& Taskinen, K. 1993: Home range of the raccoon dog (Nyctereutes procyonoides) in southern Finland. - J. Zool. London 231: 95-106.

Kauhala, K. \& Holmala, K. 2006: Contact rate and risk of rabies spread between medium-sized carnivores in southeast Finland. - Ann. Zool. Fennici 43: 348-357.

Kauhala, K., Holmala, K., Lammers, W. \& Schregel, J. 2006: Home ranges and densities of medium-sized carnivores in south-east Finland, with special reference to rabies spread. - Acta Theriol. 51: 1-13. 
Kauhala, K. \& Holmala, K. 2008: Habitat use of the domestic cat in summer in southeast Finland - discussion of the cat's role in the wild. - Suomen Riista 53: 25-41. [In Finnish with English summary].

Kauhala, K., Laukkanen, P. \& von Rége, I. 1998: Summer food composition and food niche overlap of the raccoon dog, red fox and badger in Finland. - Ecography 21: 457-463.

Kauhala, K. \& Tiilikainen, T. 2002: Radiolocation error and the estimates of home range size, movements and habitat use: a simple field test. - Ann. Zool. Fennici 39: 317-324.

Kenward, R. E. 1992: Quantity versus quality: programmed collection and analysis of radio-tracking data. - In: Priede, I. G. \& Swift, S. M. (eds.), Wildlife telemetry: remote monitoring and tracking of animals: 231-246. Ellis Horwood, New York, USA.

Kenward, R. E. 2001: A manual for wildlife radio tagging. - Academic Press, London.

Kenward, R. E., South, A. B. \& Walls, S. S. 2003: Ranges6 v. 1.2: For the analysis of tracking and location data.Anatrack Ltd., Wareham, UK.

Kowalczyk, R., Bunevich, A. N. \& Jedrzejewska, B. 2000: Badger density and distribution of setts in Bialowieza Primeval Forest (Poland and Belarus) compared to other European populations. - Acta Theriol. 45: 395-408.

Kruuk, H. \& Parish, T. 1982: Factors affecting population density, group size and territory size of the European badger, Meles meles. - J. Zool. London 196: 31-39.

Kurki, S., Nikula, A., Helle, P. \& Lindén, H. 1998: Abundances of red fox and pine marten in relation to the composition of boreal forest landscapes. - J. Anim. Ecol. 67: 874-886.

Lovari, S., Lucherini, M. \& Crema, G. 1996: Individual variations in diet, activity and habitat use of red fox in a Mediterranean rural area. - Journal of Wildlife Research 1: 24-31.

Lucherini, M. \& Lovari, S. 1996: Habitat richness affects home range size in the red fox Vulpes vulpes. - Behavioural Processes 36: 103-106.

Nasimovich, A. A. \& Isakov, Yu. А. [Насимович, А. А. \& Исаков, Ю. А.] 1985: [Arctic fox, fox, raccoon dog: distribution of stocks, ecology, use and preservation]. Nauka, Moscow. [In Russian].

Odum, E. P. \& Kuenzler, E. J. 1955: Measurement of territory home range size in birds. - The Auk 72: 128-137.

Palphramand, K. L., Newton-Cross, G. \& White, P. C. L. 2007: Spatial organization and behaviour of badgers (Meles meles) in a moderate-density population. Behav. Ecol. Sociobiol. 61: 401-413.

Pool, G. E. \& Hacker, C. S. 1982: Geographical and seasonal distribution of rabies in skunks, foxes and bats in Texas. - Journal of Wildlife Diseases 18: 405-418.

Porter, W. F. \& Church, K. E. 1987: Effects of environmental pattern on habitat preference analysis. $-J$. Wildl. Manage. 51: 681-685.

Roper, T. J., Shepherdson, D. J. \& Davies, J. M. 1986: Scent marking with faeces and anal secretion in the European badger (Meles meles): seasonal and spatial characteristics of latrine use in relation to territoriality. Behaviour 97: 94-117.

Saunders, G., White, P. C. L. \& Harris, S. 1997: Habitat utilization by urban foxes (Vulpes vulpes) and the implications for rabies control. - Mammalia 61: 497-510.

Seiler, A. 1992: Einfluss der Jahreszeiten auf Biotopnutzung und Nahrungswahl von Dachsen in Mittelschweden. - M.Sc. thesis, Univeristy of Göttingen, Germany \& Grimsö Wildlife Reserarch Station, Sweden.

Seiler, A., Lindström, E. \& Stenström, D. 1995: Badger abundance and activity in relation to fragmentation of foraging biotopes. - Ann. Zool. Fennici 32: 37-45.

Smith, G. C. 2002: The role of the badger (Meles meles) in rabies epizootiology and the implications for Great Britain. - Mammal Rev. 32: 12-25.

Smith, G. C. \& Wilkinson, D. 2002: Modelling disease spread in a novel host: rabies in the European badger Meles meles. - J. Appl. Ecol. 39: 865-874.

Smith P. G. 2006. Compos analysis version 6.2. user's guide [ver. 6.2.3]. - Smith Ecology Ltd., available at http:// www.smithecology.com/software.htm.

Smith, P. G. \& Racey, P. A. 2005: Optimum effort to estimate habitat use when the individual animal is the sampling unit. - Mammal Rev. 35: 295-301.

Steck, F. \& Wandeler, A. 1980: The epidemiology of fox rabies in Europe. - Epidemiological Review 2: 71-96.

Vicente, J., Delahay, R. J., Walker, N. J. \& Cheeseman, C. L. 2007: Social organization and movement influence the incidence of bovine tuberculosis in an undisturbed high-density badger Meles meles population. - J. Anim. Ecol. 76: 348-360.

Ward, O. G. \& Wurster-Hill, D. H. 1990: Nyctereutes procyonoides. - Mammalian Species 358: 1-5.

Wandeler, A. I., Müller, J., Wachendörfer, G., Schale, W., Förster, U. \& Steck, F. 1974: Rabies in wild carnivores in central Europe, III. Ecology and biology of the fox in relation to control operations. - Zentralblatt für Veterinärmedizin B 21: 765-773.

Westerling, B. 1991: Rabies in Finland and its control 1988-90. - Suomen Riista 37: 93-100. [In Finnish with English summary].

White, P. C. L., Harris, S. \& Smith, G. 1995: Fox contact behaviour and rabies spread: a model for the estimation of contact probabilities between urban foxes at different population densities and its implications for rabies control in Britain. - J. Appl. Ecol. 32: 693-706.

WHO 2006: Country summaries of rabies cases, 2006 total. - Rabies Bulletin Europe 30: 10.

Woloch, A. \& Rozenko, N. 2007: Die Akklimatisation des Mardeshundes (Nyctereutes procyonoides Gray, 1834) in der Südukraine. - Beiträge zur Jagd- und Wildforschung 32: 409-422.

Worton, B. J. 1989: Kernel methods for estimating the utilization distribution in home range studies. - Ecology 70: 164-168. 